\title{
APPROXIMATE $\omega$-ORTHOGONALITY AND $\omega$-DERIVATION
}

\section{MARYAM AMYARI AND MARZIEH MORADIAN KHIBARY}

Abstract. We introduce the notion of approximate $\omega$-orthogonality (referring to the numerical radius $\omega$ ) and investigate its significant properties. Let $T, S \in \mathbb{B}(\mathscr{H})$ and $\varepsilon \in[0,1)$. We say that $T$ is approximate $\omega$-orthogonality to $S$ and we write $T \perp_{\omega}^{\varepsilon} S$ if

$$
\omega^{2}(T+\lambda S) \geqslant \omega^{2}(T)-2 \varepsilon \omega(T) \omega(\lambda S), \quad \text { for all } \lambda \in \mathbb{C} .
$$

We show that $T \perp_{\omega}^{\varepsilon} S$ if and only if $\inf _{\theta \in[0,2 \pi)} D_{\omega}^{\theta}(T, S) \geqslant-\varepsilon \omega(T) \omega(S)$ in which $D_{\omega}^{\theta}(T, S)=$ $\lim _{r \rightarrow 0^{+}} \frac{\omega^{2}\left(T+r e^{i \theta} S\right)-\omega^{2}(T)}{2 r}$; and this occurs if and only if for every $\theta \in[0,2 \pi)$, there exists a sequence $\left\{x_{n}^{\theta}\right\}$ of unit vectors in $\mathscr{H}$ such that

$$
\lim _{n \rightarrow \infty}\left|\left\langle T x_{n}^{\theta}, x_{n}^{\theta}\right\rangle\right|=\omega(T) \text { and } \lim _{n \rightarrow \infty} \operatorname{Re}\left\{e^{-i \theta}\left\langle T x_{n}^{\theta}, x_{n}^{\theta}\right\rangle \overline{\left\langle S x_{n}^{\theta}, x_{n}^{\theta}\right\rangle}\right\} \geqslant-\varepsilon \omega(T) \omega(S),
$$

where $\omega(T)$ is the numerical radius of $T$.

Mathematics subject classification (2010): 47A12, 46B20, 46C05.

Keywords and phrases: Hilbert space, numerical radius, approximate $\omega$-orthogonality, $\omega$-derivation.

\section{REFERENCES}

[1] C. Alsina, J. Sikorska, And M. Santos Tomás, Norm derivatives and characterizations of inner product spaces, World Scientific Publishing Co. Pte. Ltd., Hackensack, NJ, 2010.

[2] J. ChMielińs KI, On an $\varepsilon$-Birkhoff orthogonality, JIPAM. J. Inequal. Pure Appl. Math. 6, 3 (2005), Article 79, 7 pp.

[3] J. Chmielińs KI, T. STYPUŁA, AND P. WóJCIK, Approximate orthogonality in normed spaces and its applications, Linear Algebra Appl. 531 (2017), 305-317.

[4] S. S. DRAGOMIR, Inequalities for the numerical radius of linear operators in Hilbert spaces, Springer Briefs in Mathematics, Springer, Cham, 2013.

[5] S. S. DRAGOMIR, On approximation of continuous linear functionals in normed linear spaces, An. Univ. Timişoara Ser. Ştiinţ. Mat. 29, 1 (1991), 51-58.

[6] S. G. Dastidar, AND G. H. Bera, On numerical radius of some matrices, Int. J. Math. Anal. 12, 1 (2018), 9-18.

[7] K. HE, J. C. HoU, AND X. L. ZHANG, Maps preserving numerical radius or cross norms of products of self-adjoint operators, Acta Math. Sin. (Engl. Ser.) 26, 6 (2010), 1071-1086.

[8] O. Hirzallah, F. Kittaneh, AND K. Shebrawi, Numerical radius inequalities for certain $2 \times 2$ operator matrices, Integral Equation Operator Theory 71, 1 (2011), 129-147.

[9] G. Lumer, Semi-inner-product spaces, Trans. Amer. Math. Soc. 100 (1961), 29-43.

[10] A. MAL, K. PAUL, AND J. SEN, Orthogonality and numerical radius inequalities of operator matrices, arXiv:1903.06858.

[11] K. PAUL, D. SAIN, AND A. MAL, Approximate Birkhoff-James orthogonality in the space of bounded linear operators, Linear Algebra Appl. 537 (2018), 348-357.

[12] K. PAUL, AND S. BAG, On numerical radius of a matrix and estimation of bounds for zeros of a polynomial, Int. J. Math. Math. Sci. (2012), Art. ID 129132, 15 pp.

[13] M. S. Moslehian, AND A. Zamani, Characterizations of operator Birkhoff-James orthogonality, Canad. Math. Bull. 60, 4 (2017), 816-829. 
[14] J. Rooin, S. Karami, AND M. Ghaderi Aghideh, A new approach to numerical radius of quadratic operators, Ann. Funct. Anal. 11, 3 (2020), 879-896.

[15] R. TANAKA, AND D. SAIN, On symmetry of strong Birkhoff orthogonality in $B(\mathscr{H}, \mathscr{K})$ and $K(\mathscr{H}, \mathscr{K})$, Ann. Funct. Anal. 11, 3 (2020), 693-704.

[16] M. Torabian, M. Amyari, And M. Moradian Khibary, More on $\omega$-orthogonalities and $\omega$ parallelism, Linear Multilinear Algebra, doi: 10.1080/03081087.2020.1809618. 